\title{
Finite element analysis of the interface defect in ceramic-metal assemblies: Alumina-Silver
}

\author{
Lamia Hadid \\ LMPM, Mechanical Engineering Department, University of Sidi Bel Abbes, Sidi Bel Abbes 22000, Algeria \\ l.hadid@outlook.fr, bttp:/ / orcid.org/0000-0002-9628-193X
}

\section{Farida Bouafia}

LMPM, Mechanical Engineering Department, University of Sidi Bel Abbes, Sidi Bel Abbes 22000, Algeria Mechancal Engineering Department, University centre of Ain Temoubent 46000, Algeria

fbonafia2011@yahoo.fr, bttp://orcid.org/0000-0002-1695-1500

\section{Boualem Serier}

LMPM, Mechanical Engineering Department, University of Sidi Bel Abbes, Sidi Bel Abbes 22000, Algeria boualems@yahoo.fr,http:/ /orcid.org/0000-0002-1460-9322

\author{
Sardar Sikandar Hayat* \\ Department of Physics, International Islamic University, Islamabad 44000, Pakistan \\ sikandariub@yahoo.com, bttps://orcid.org/0000-0001-6018-7354
}

\begin{abstract}
In the present work, the finite element analysis was employed to study the distribution of mechanical stress generated in metal-ceramic bimaterial. A micromechanical model is proposed to explain a phenomenon of defect observed in the metal-ceramic interface. The distribution of this stress in the ceramic around this defect was the subject of a numerical analysis using the finite element method. The analysis has been extended to the effect of defect-defect interaction, defect size and form.
\end{abstract}

KEYwORDS. Finite element method; Mechanical stress; Defects; Interface; Metal; Ceramic.

\section{OPEN ACCESS}

Citation: Hadid, L., Bouafia, F., Serier, B., Sikandar Hayat, S., Finite element analysis of the interface defect in ceramic-metal assemblies: Alumina-Silver, Frattura ed Integrità Strutturale, 53 (2020) 1-12.

Received: 06.09.2019

Accepted: 27.04 .2020 Published: 01.07.2020

Copyright: (C) 2020 This is an open access article under the terms of the CC-BY 4.0, which permits unrestricted use, distribution, and reproduction in any medium, provided the original author and source are credited.

\section{INTRODUCTION}

etal-ceramic bi-materials offer superior properties over conventional alloys and have been widely studied because of their many potential applications. Ceramics such as zirconia, silicon carbides, silicon nitrides and alumina find a great number of applications in the field of mechanics and thermo-mechanics. The alumina remains practically the technical most current ceramics. In addition to the mechanical applications, it also gains first place 
in the electronics industry and electro-technical due to its interesting electrical properties such as great resistivity, significant dielectric constant and weak dielectric loss factor.

Very often to benefit the maximum of these advantages, it is necessary to bind ceramics and more particularly alumina with metals and their alloys. Under the simultaneous action of the temperature and the elaboration constraint of the bimaterial, the metal deforms plastically and becomes encrusted in the roughness defects of the ceramic. This incrustation leads to a good mechanical attachment between these two protagonists and ensures very good adhesion between metal and ceramic.

The joining of ceramics with metals is inherently difficult because of their distinctly different properties. During recent past years, considerable studies have been devoted to the technology development of ceramic/metal joining. It has been led to significant successes [1]. Dissimilar materials need to be joined together in many technical areas. One example of the ceramic to metal joint combines the wear resistance, high temperature strength and thermal or electrical resistance of the ceramic with the ductility of the metal. Due to the difference of the elastic properties and the thermal expansion coefficients of the ceramic and metal,-high stresses occur at the intersection of edges which leads the interface of the joint under mechanical or thermal loading [2-3].

The joining of ceramics with metals is a critically important technology for the effective use of advanced materials [4]. Metal-ceramic interfaces have wide applications, and the interface fractures play an important role in determining mechanical behaviours of related structures [5]. The study of the interface separation behaviours of interfaces with the atomic vacancy and dislocations indicates that the interface strength decreases for the interfaces with defects, and the defects decrease the catastrophic tendency [5]. Joining dissimilar materials implies property mismatches and structure discontinuities [6]. Interfaces must typically sustain mechanical and thermo-elastic stresses without failure. Consequently, they exert an important influence on the performance of the material [7-8].

Due to differences in thermal and mechanical properties, the stresses and strains can develop near a ceramic-metal interface stress concentration. This can result in the plastic deformation of metal during both fabrication and under subsequent thermal or mechanical loading (cracking within the ceramic). Tremendous efforts have been made to understand these phenomena [7-12]. Nevertheless, the effects of material properties and specimen geometry on stress and strain distributions, and fracture mechanisms are reasonably well understood.

The realization of Silver-Alumina junction is made in solid state. The mechanical resistance of this assembly depends primarily on the conditions of its elaboration, particularity on the atmosphere of elaboration. The fracture resistance is generally determined according to the nature of the elaboration the atmosphere of this kind of junctions [12-14]. Silver is a noble metal and reacting with the alumina does not give an intermediate compound. The assembly of this metal in alumina form no-reactive junction. The objective of this study is to numerically analyse silver-alumina junction by the finite element method. The effect of the interface defect between the metal and ceramic on the stress level has been studied in this work.

\section{FINITE ELEMENT MODEL}

7 he finite element model is already explained in our previous work [15-17]; however, salient features of the model which is used in this work are discussed here. A three-dimensional finite element analysis is developed for this investigation. A 2-D schematic view of the metal / ceramic bi-materials with an interface defect is shown in Fig. 1(a). One half of the model is selected as the analysis model (because of the symmetry) in order to reduce the calculation time (see Fig. 1(b)). The geometrical characteristics of the structure are the length $L(L=350 \mu \mathrm{m})$, the width $w$ and the thickness $\left(e_{1}\right.$ and $e_{2}$ ) such as $L / e_{1}=7, e_{2} / e_{1}=6, L / w=2$. The plate is subjected to a uniformly distributed tensile load with $P=70 \mathrm{MPa}$. The diameter of the interface defect is $50 \mu \mathrm{m}$ which characterize an average size of interface defect site. These defects are simulated with half-spherical cavities located at alumina interface with well-defined size ((see Fig. 1(e)). Numerical modelling has been taken using the ABAQUS [18] finite element program. The precision of numerical computation is strongly related to the quality of the mesh in the structure. Additionally, due to the stress concentrations expected at the metal/ceramic interface, the mesh is refined at this zone and a 4-node linear tetrahedron (C3D4) finite element is used for the model (see Fig. 1(c)). The finite element model with 75801 elements is shown in Fig. 1(c). It has a fine grid at the metal/ceramic interface. The refinement of the mesh also shows its influence on the accuracy of numerical results, and number of elements higher than 75801 leads to similar and much more precise values (Fig. 2). The surface between the metal and the ceramic is defined as the surface to surface contact (perfect surface). Here, the ceramic has been selected as a slave and the metal as a master surface. 
Silver bonded to alumina is selected in this study. Pure silver is defined as an elastic - plastic material (Fig. 3) with a value of the modulus of elasticity $\mathrm{E}=81.90 \mathrm{GPa}$ and Poisson's ratio $\nu=0.31$. The behaviour of alumina is considered as an isotropic elastic material. Alumina is assumed to be elastic with modulus of elasticity value E= 390 GPa and Poisson's ratio $\nu=0.25$.

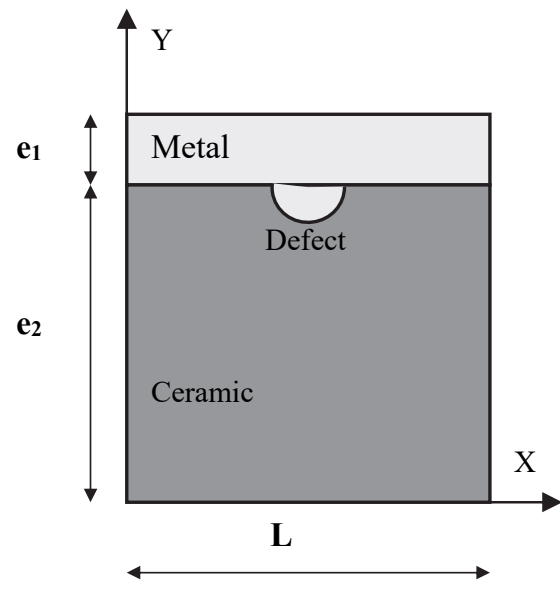

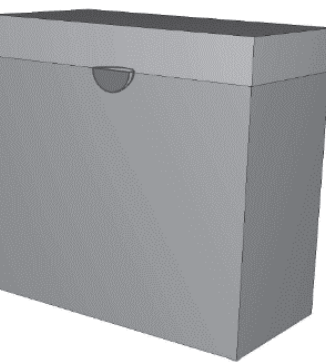

(b)

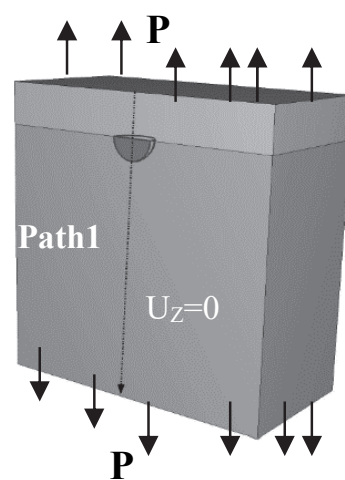

(d)

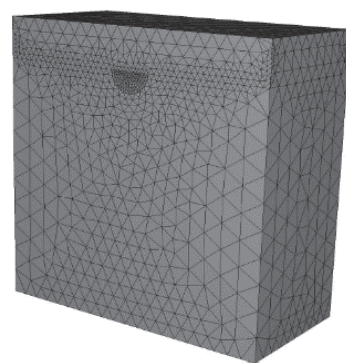

(c)

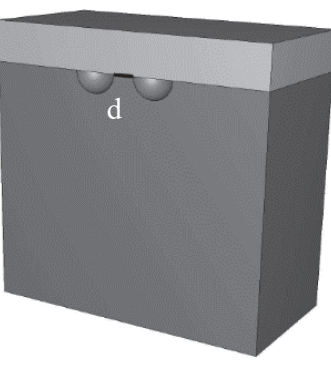

(e)

Figure 1: (a) A 2-D schematic view of metal/ceramic with the site of interface defect, (b) Geometry of model, (c) Finite element mesh, (d) Boundary condition and loading condition and (e) site of interface defect-defect interaction.

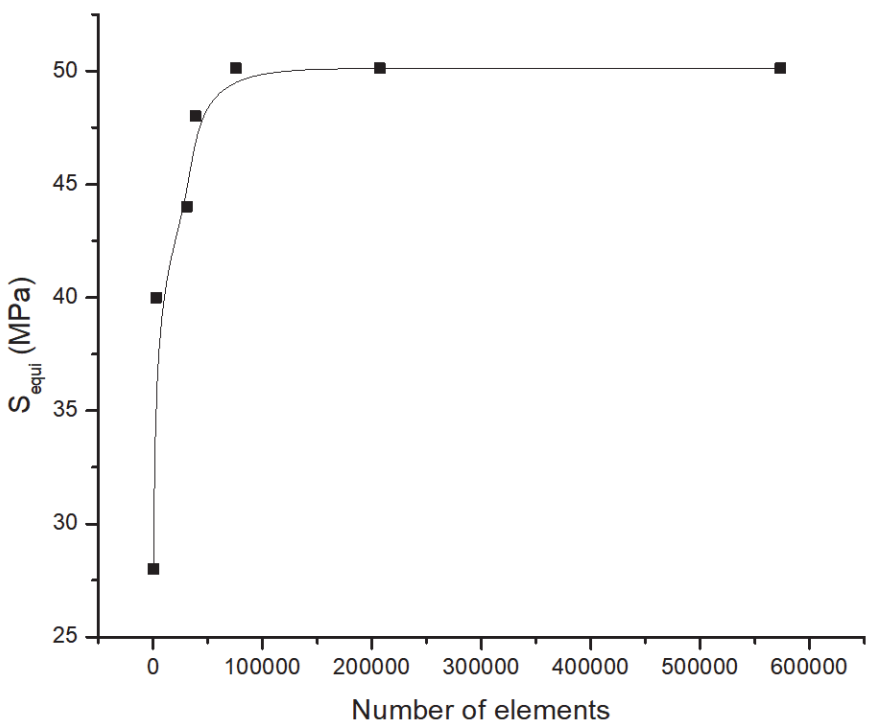

Figure 2: Effect of mesh size convergence on ceramic/defect interface for $\mathrm{P}=70 \mathrm{MPa}$. 


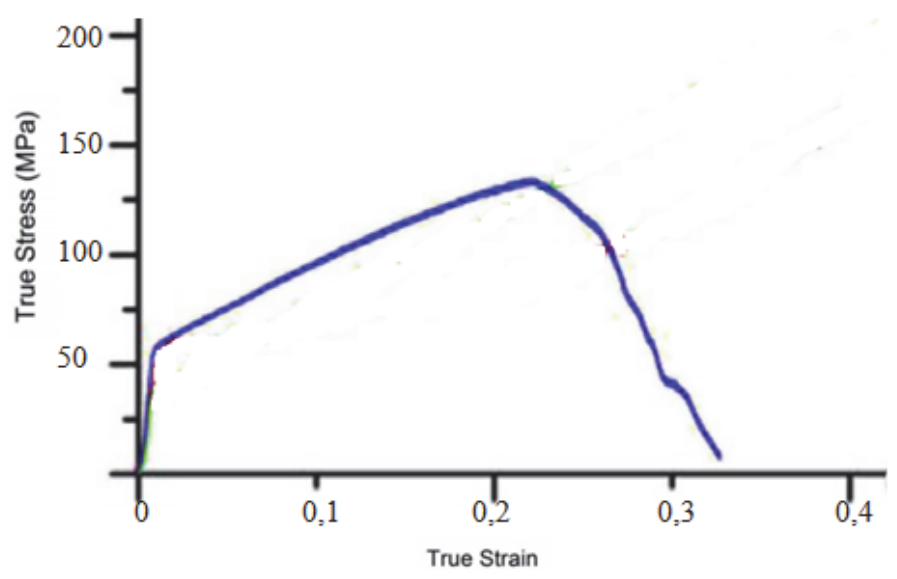

Figure 3: The true stress-strain curve of pure silver [19].

\section{RESULTS AND DISCUSSION}

7 he simultaneous action of the pressure and temperature (thermo-compression) during the elaboration of connecting ceramics-metal involves a plastic flow of the metal. The plastic flow speed of deformation is overall high as these two physical parameters are significant. This plastic flow leads to a friction interface between ceramics and metal. Thus involve a significant wrenching of the surface grains of alumina contact. In this context, here the results are discussed to numerically analyse the stress distribution near the interface defect using tri- dimensional the finite element method.

(a): $\mathbf{S}_{\text {equi }}$

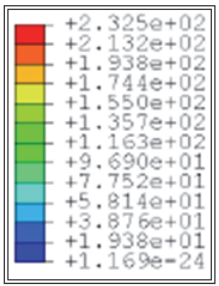

(c) : $\mathbf{S}_{\mathbf{y y}}$

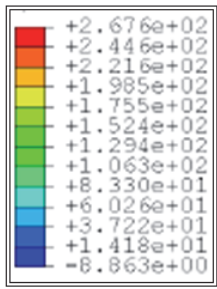

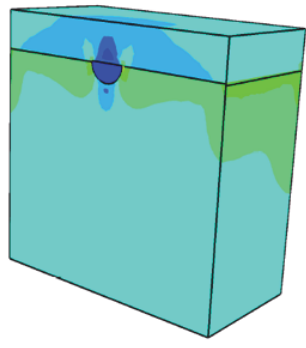

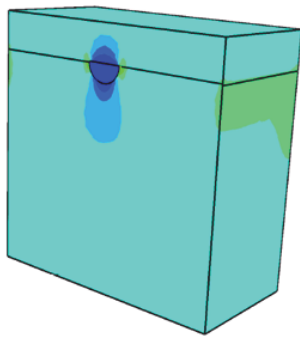

(b): $\mathbf{S}_{\mathbf{x x}}$

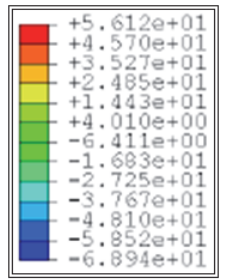

(d): $\mathbf{S}_{\mathbf{z z}}$
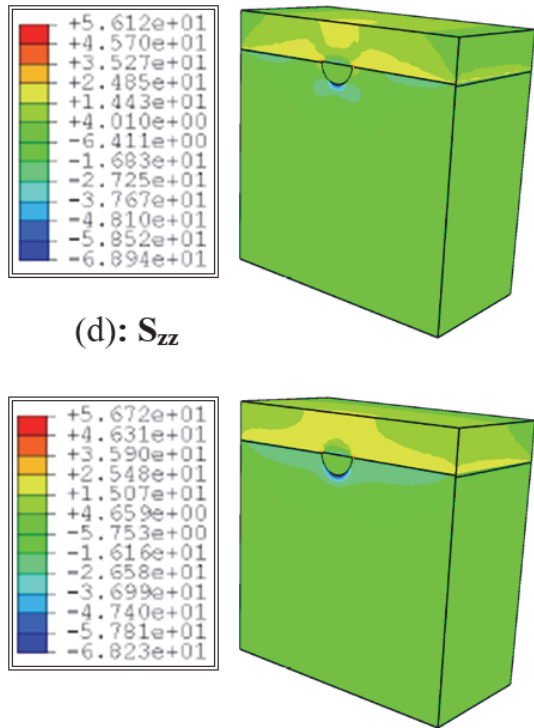

Figure 4: Von-Mises equivalent and normal stress distribution for $\mathrm{P}=70 \mathrm{MPa}$.

\section{Stresses distribution}

The distribution of normal and Von Mises equivalent stresses for the silver and alumina near the interface defect during the preparation of their junction is represented in Fig. 4. The normal stress induced along the $\mathrm{x}$-direction is highly concentrated on the metal at the interface near the edge of the connection, while the volume of silver is in the opposite direction of this site (see Fig. 4(b)). The stress generated along the z-direction is on the same level and its distribution is comparable to that induced following the first axis (x-axis) of the assembly (see Fig. 4(d)). The normal stress along the y- 
axis, which is the axis of application of mechanical loading, is at a much higher level than the other two normal stresses, which are highly concentrated for the alumina and silver in the neighborhood near the defect (see Fig. 4(c)). The Von Mises equivalent stress is highly concentrated near the site. Its distribution reflects the normal stresses (see Fig. 4(a)). The illustrations of results in Fig. 4 clearly show that the defect is at a special place of stress concentration by notch effect.

\section{Effect of loading}

Fig. 5 shows the variation of normal stresses for the ceramic and metal near the defect as a function the normalized distance (X-values correspond to each point's distance along the path as a fraction of the total length of the path (see Fig.1d)) and according to the applied mechanical load. These stresses are heavily concentrated around the interfacial defects. Interfacial defects effects are increased with increasing applied stress. This type of loading compresses the cavity along $\mathrm{x}$ - and z-direction. The compression ratio becomes higher when the intensity of loading increases. These stresses vanish for the defect. Stresses along the y-direction of mechanical stress set the cavity in tension. The intensity of these stresses holds more importance than those for the other two axes of the structure. The variation of Von Mises stresses around the defect as a function of the applied stress is shown in Fig. 5(a). The analysis of this Figure clearly shows that the presence of this defect on the surface of the ceramic-related metal plays a leading role of stress concentration, whose intensity increases with the increase in mechanical loading of the junction.
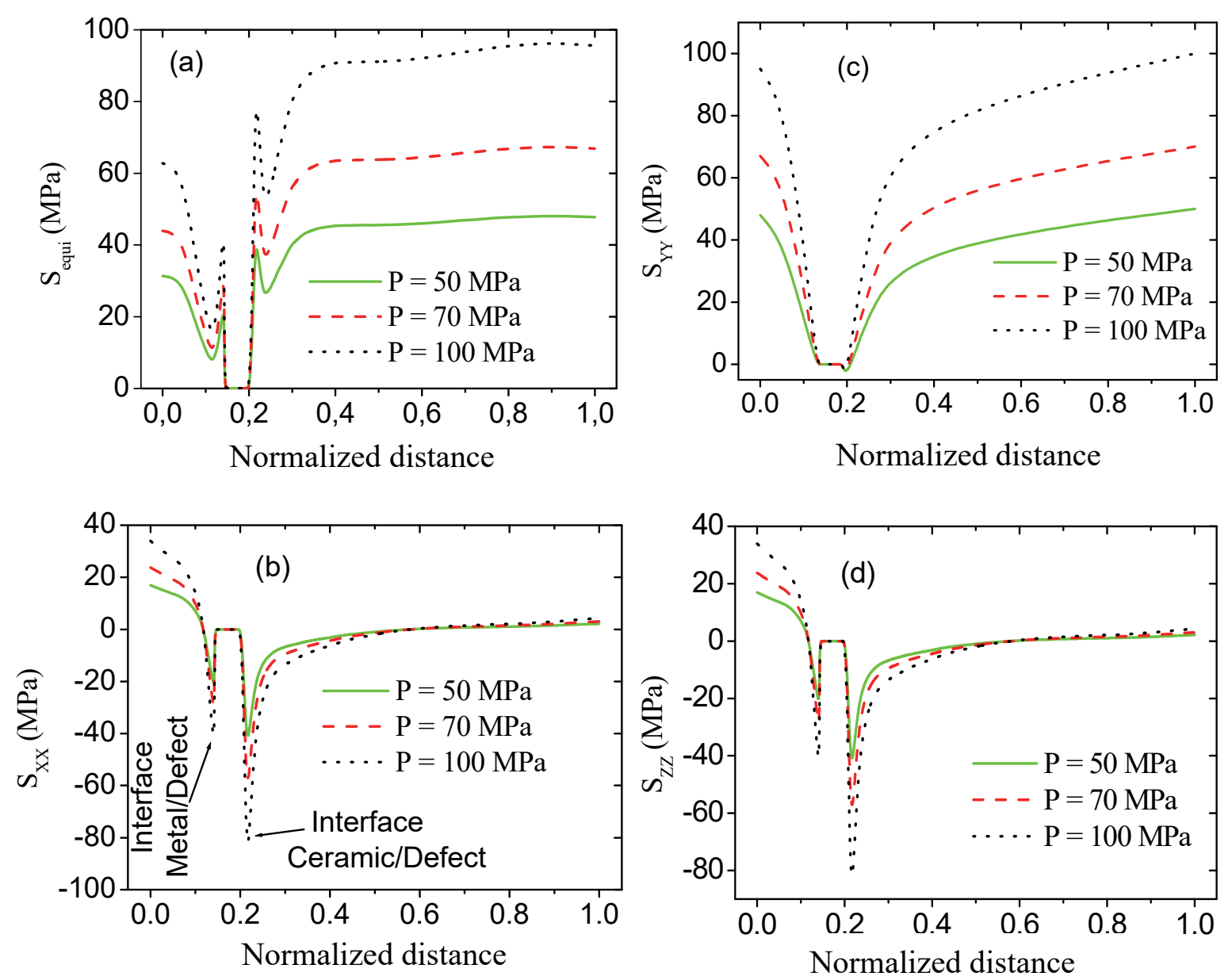

Figure 5: Variation of equivalent and normal stresses according to mechanical loading.

\section{Effect of defect size}

The size of interfacial defect does not merely determine the distribution and the level of the stresses of this defect, nevertheless, also measures the surface of effective adhesion. Its analysis carries great importance for the performance and the mechanical resistance of the junction. Fig. 6 illustrates the variation of induced normal stresses nearby to the defect applying a mechanical stress as a function of its diameter. This Figure shows that large defects induce more significant 
stresses. These results show that the stress concentration increases proportionally with the increase of the defect size to reach the maximum value for the biggest size. Such a behaviour can present a risk of decoherence of the junction. The site of the interface defect (seat of stress concentration) is a privileged place of initiation and propagation of cracks.

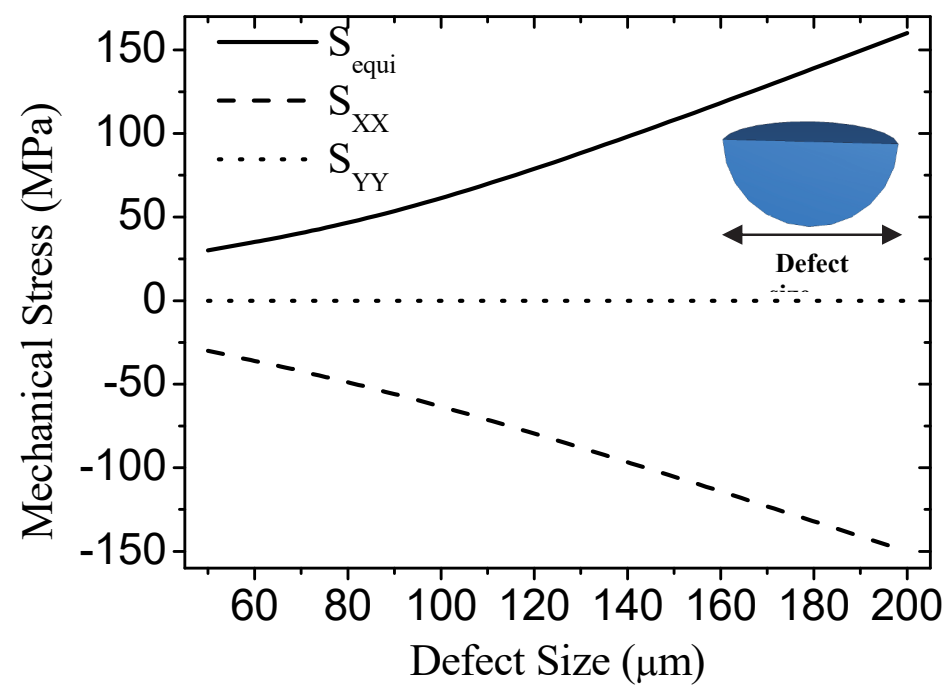

Figure 6: Variation of mechanical stresses according to a defect size in Metal/defect interface for $\mathrm{P}=70 \mathrm{MPa}$

The variation of stress concentration factor as a function of the interface defect size is represented in Fig. 7 . This Figure well illustrates that this factor varies almost linearly with the variation in size. This clearly shows that the presence of large defects on the surface of the ceramic can lead to the initiation and the propagation of cracks and consequently to the damage of alumina-silver assembly by cohesive or adhesive rupture depending the mechanical strength of the interface. Thus, they are able to lead to a cohesive or adhesive rupture, according with the resistance.

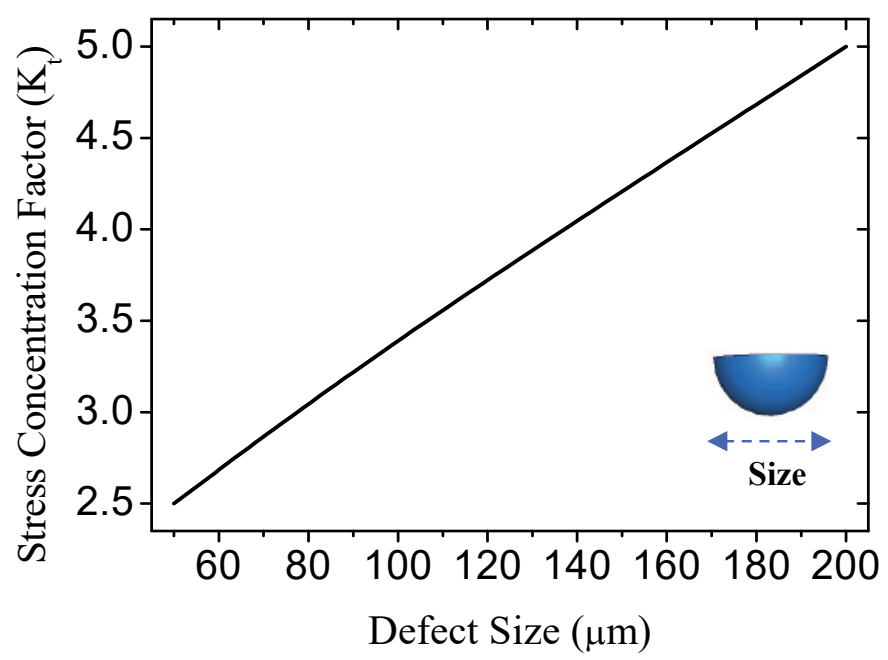

Figure 7: Variation of stress concentration factor according to a defect size for $\mathrm{P}=70 \mathrm{MPa}$.

\section{Stresses distribution around the defect}

The level of stresses around the site of interface defect exploits a dominating role in the start-up and the performance of the ceramics-metal junction. Its analysis carries great importance for the mechanical resistance and the durability of this junction.

Figs. 8(b), 8(c) and 8(d) represent the distribution of induced normal stresses according to three axes of the structure along the perimeter (path 2) of the interfacial defect (see Fig. 8(a)). The analysis of this Figure shows that according to the $\mathrm{x}$-direction, at the ends, i.e. in the vicinity of the interface with metal, (when $\theta<20^{\circ}$ ) the defect is subject to the normal stresses of tension, and far from this zone to compressive stresses. Along the direction of applied load, which is y- 
direction, the normal stresses of tension are higher at the defect $/$ metal interface (when $\theta=0^{\circ}$ and $\theta=180^{\circ}$ ) and very low in the zone far from the plane of the alumina-silver junction (when $\theta=90^{\circ}$ ) (see Fig. 8(c)). A contrary behaviour is observed along the z-direction; indeed, the compression stresses are intensively concentrated in ceramics, $\left(\right.$ when $\left.\theta=90^{\circ}\right)$, while their level decreases considerably in the mid of this interface (when $\theta=0^{\circ}$ and $\theta=180^{\circ}$ ) (see Fig. 8(d)). The tangential stresses are most significant specific to the xoy planes of the assembly. The highest stresses are localized at $\theta=$ $45^{\circ}$ and $135^{\circ}$ (see Fig. $8(\mathrm{e})$ ).
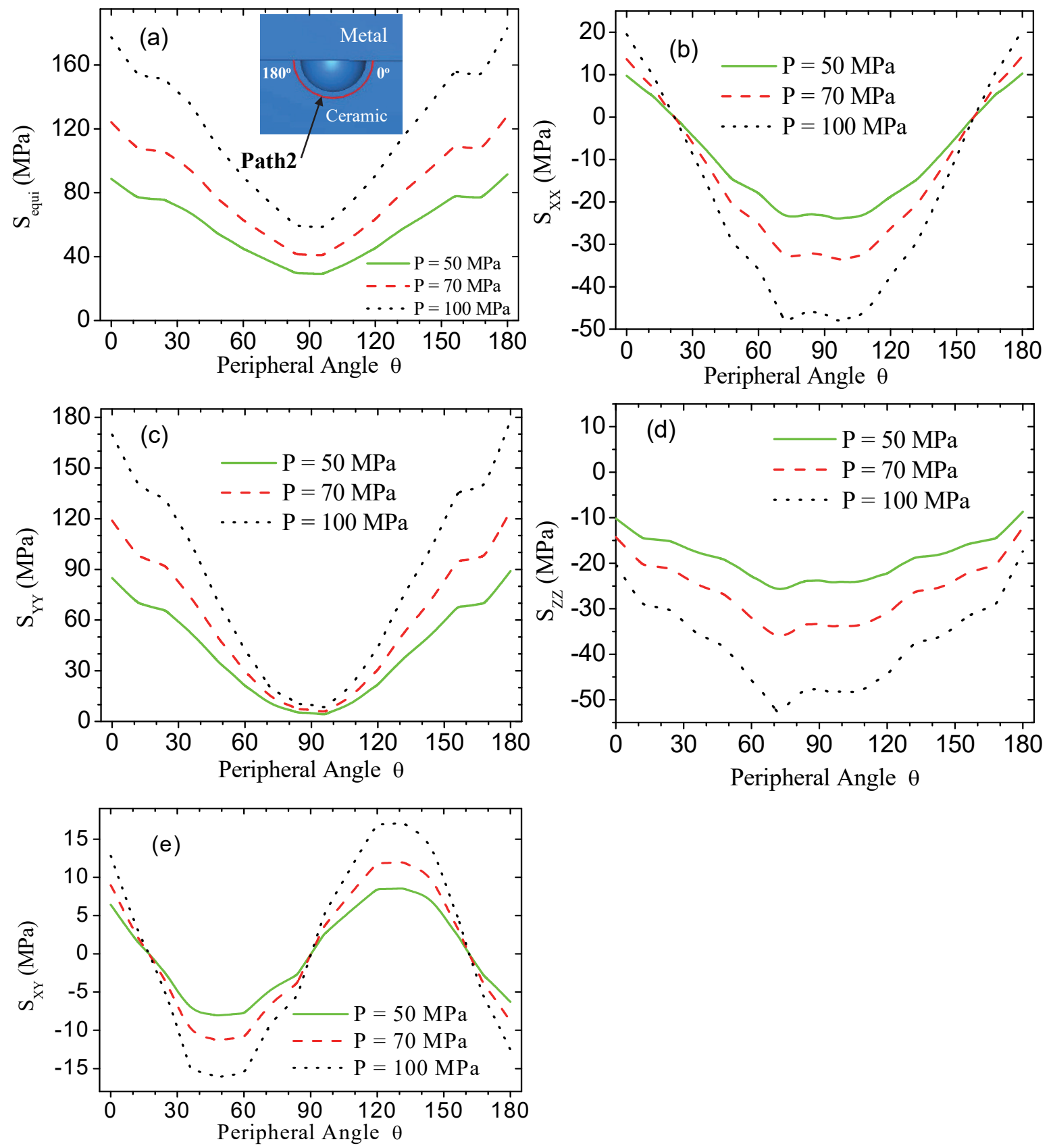

Figure 8: Variation of equivalent, normal and shear stresses according to peripheral angle and mechanical loading.

\section{Effect of defect geometry}

The effect of the defect form, which is defined by the $x / y$ ratio, is analysed, and the effect of the defect volume on the distribution of equivalent and normal stresses near to the interface with metal is characterized. This analysis is made for an invariable size $x$ along path 1 (see Fig. 1). The obtained results are represented in Figs. 9 and 10. 

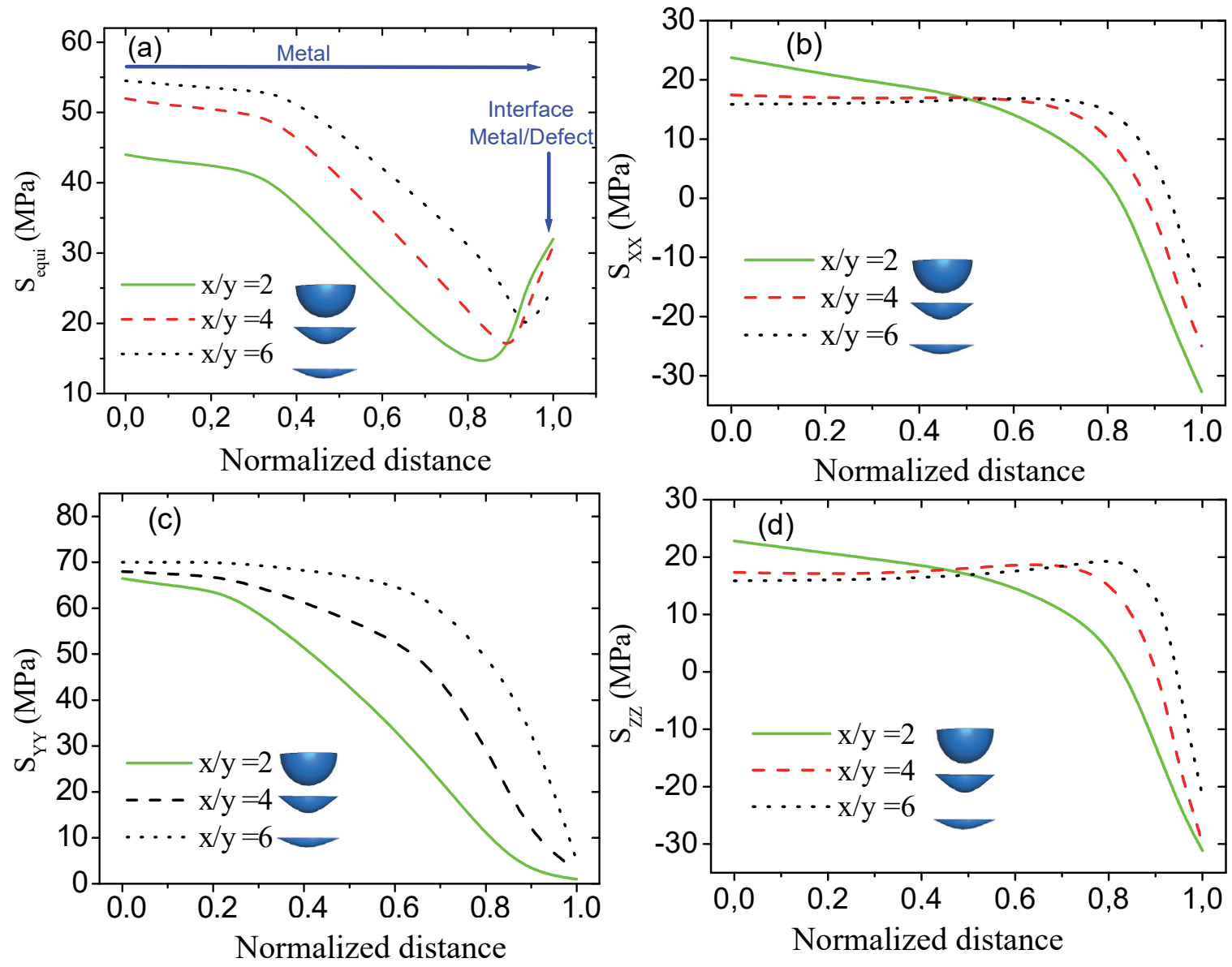

Figure 9: Variation of equivalent and normal stresses depending on defect geometry in Metal.

The influence of the parameter $y$ on the level of the normal stresses is generated in the silver along $\mathrm{x}$ - and $\mathrm{z}$ - direction of the junction. Along these directions and far from the interface, the metal is in tension, whereas in its close vicinity it is in compression. The intensity of these stresses increases with the volume of interface defect (see Figs. 9(a) and 9(c)). Along the $y$-axis, which is the direction of mechanical load application, the normal stresses decrease approaching the interface with ceramics. An increase in the $x / y$ ratio involves a light amplification of these stresses. Their amplitude is annulled in the plane of the junction (see Fig. 9(b)). The Von Mises equivalent stress in the metal gradually decreases towards the interface with alumina, then grows slightly near to this defect. This stress is overall more significant as the $\mathrm{x} / \mathrm{y}$ ratio increases (see Fig. 9(d)).

The distribution and level of the Von Mises and normal stresses induced in alumina as a function of the $x / y$ ratio are represented in Fig. 10. The induced normal stresses along $x$ - and $z$-direction seems not to dependent on the shape of the interface defect. Indeed, the intensity of these stresses practically does not vary with the variation in the $x / y$ ratio (see Figs. 10 (b) and 10(d)). An increase in the $x / y$ ratio involves an increase in the Von Mises and $y$-direction normal stresses generated in the vicinity of interface defect (see Figs. 10(a) and 10(c)).

The effect of the defect shape on the distribution of equivalent stress and its intensity is analysed in terms of stress concentration factor (see Fig. 11). This figure shows that the decrease in the parameter involves a high stress concentration factor. The interface defect having such a form is the seat of stress concentration.

\section{Effect of defect-defect interaction}

The previously obtained results show that the alumina defect is a privileged place of stress concentration whose level and distribution does not merely depend on its size, but also on its form. However, several grains are snatched by interfacial friction between these two components during the realization of metal-ceramics junction. These sites are represented by interfacial defects of spherical symmetry. This is why, an analysis of the effect of defect-defect interaction at the interfacial 
level and the distribution of stresses is carried out. The so obtained results are illustrated in Fig. 12. This last one shows the variation of Von Mises and normal stresses according to the distance separating the sites from two defects.
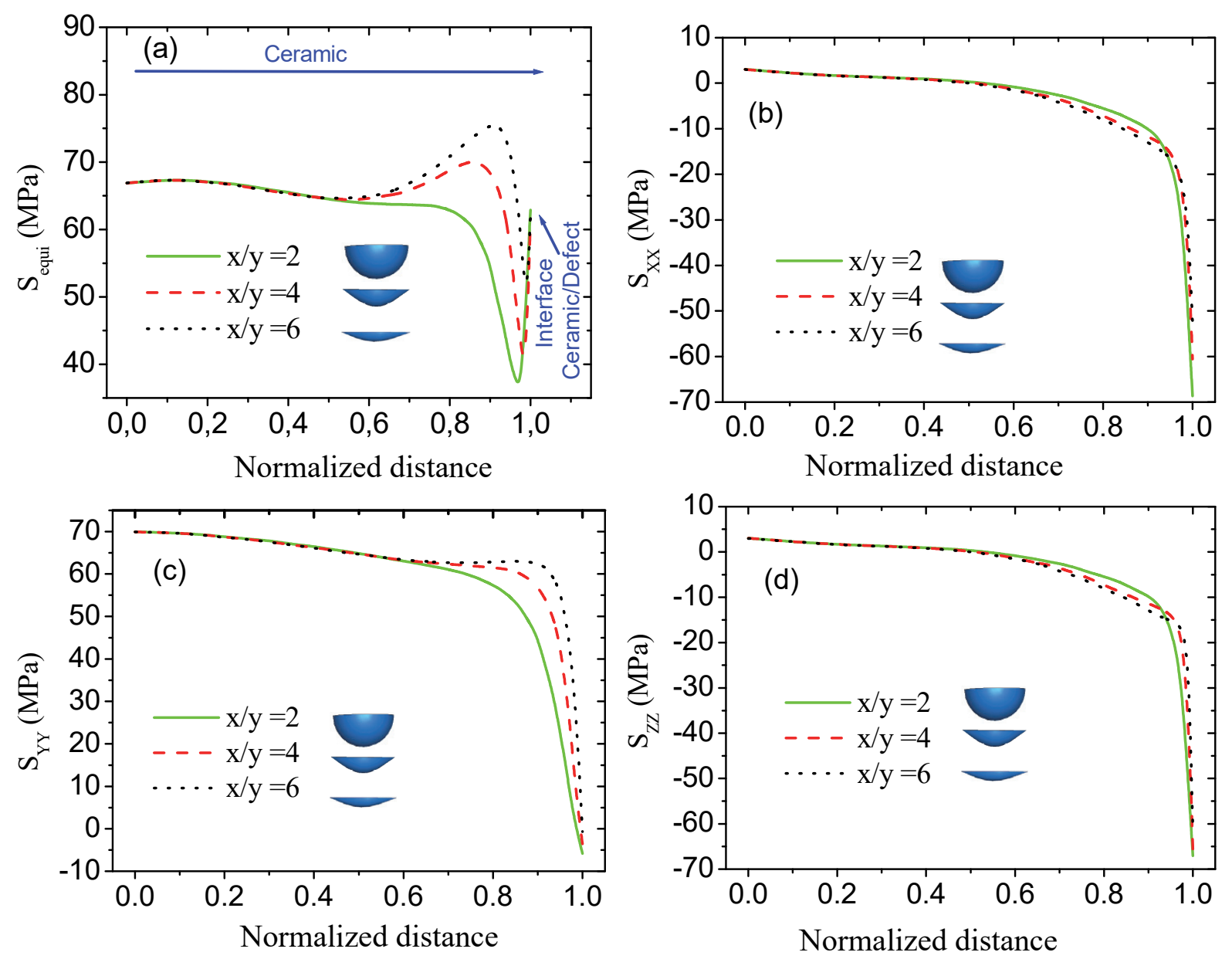

Figure 10: Variation of equivalent and normal stresses according to defect geometry in ceramic.

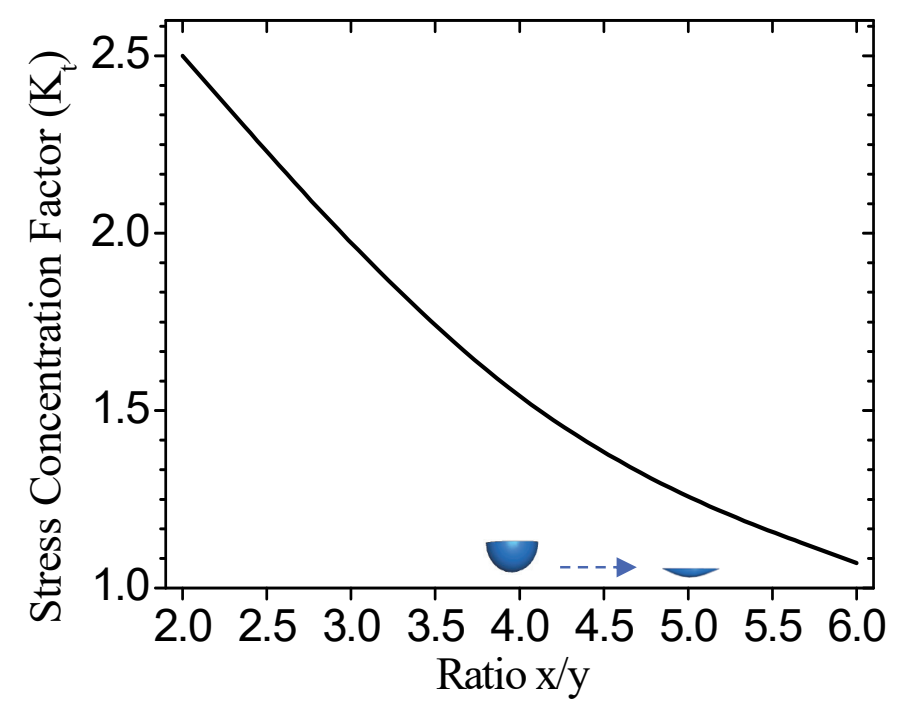

Figure 11: Variation of stress concentration factor according to defect geometry. 

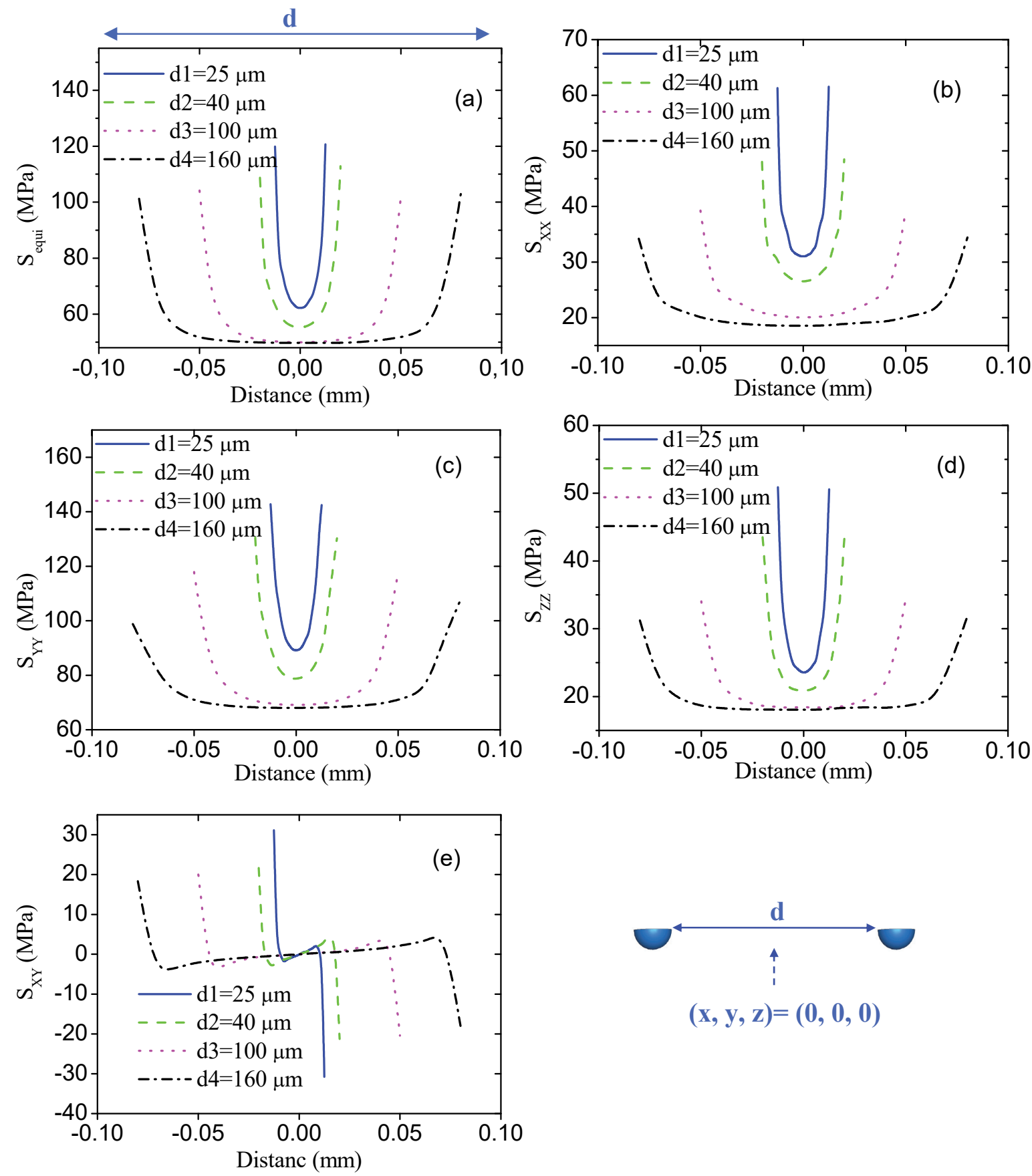

$(\mathbf{x}, \mathbf{y}, \mathbf{z})=(\mathbf{0}, \mathbf{0}, \mathbf{0})$

Figure 12: Variation of internal equivalent and normal stresses according to the defect-defect interaction for $\mathrm{P}=70 \mathrm{MPa}$.

The stress intensity induced along the $x$-and $z$-direction of the assembly grows with the reduction in the defect- defect interdistance. Indeed, bringing together these two defects leads to the intensification of these stresses. These last tend towards their maximum level when the sites of the interface defect are very close to the other one (see Figs. 12(b) and 12(c)). A tendency of an interfacial defect towards the other involves an amplification of the normal stresses which are generated along the y-direction which is requested by the external mechanical loads. Two defects are close neighbors which generate much more intense normal stresses, whose level is approximately twice more significant than that of the load applied (see Fig. 12(c)). The tangential stresses are most significantly related to the plane (x, o, y) of the structure. The level of these stresses grows with the reduction in the defect-defect inter-distance. Maximum sites of the interface defect are close to each other and the shear stresses induced in this plane are strong (see Fig. 12(e)). Fig. 12(a) shows the effect of 
this inter-distance on the amplitude of Von Mises stress. This figure shows that bringing together these sites leads to the strong intensification of equivalent stress. The results obtained in this analysis clearly show that the distance separating the sites from the defect with the metal determines the level and distribution of the stresses induced with their interface. Indeed, the more these sites are close to each others, the more their stress field is reacting between them. Thus, the amplification of these constraints is involved with the effect of the interaction. This effect is dominated when the vicinity sites are very close to each other. The distance of one of these sites compared to the others minimizes the effect of the interaction. This finally is annulled when the sites of the interface defect are very far from each other, then their stress fields are isolated from each other.

\section{CONCLUSIONS}

I $\mathrm{n}$ the present work, 3-dimensional finite element method was used to investigate the effects of the defect in metalceramic bimaterial. The results obtained in this study allow us to draw the following conclusions:

- The sites of interface defect during the elaboration by interfacial friction with the silver are the privileged places of stress concentration by notch effect. The level and the distribution of the normal, tangential and the Von Mises equivalent stresses are not dependent merely on the intensity of the mechanical loading, nevertheless, also on the size of the sites of interface defect (characteristic of the site volume). These stresses are overall higher as the volume of this site grows. The stress concentration factor grows with the increase in the volume. Thus, the coarse interface defects do concentrate more stresses relative to the small ones.

- The form which is defined by the $x / y$ ratio of this defect plays a role to determine the level of the Von Mises and normal stresses. A small ratio involves an increase in the induced normal stresses of the silver, relating to the $x$-and $z$-direction of the assembly, while a reduction of the normal stress relating to the $y$-axis. The Von Mises stress is overall weak as the $x / y$ ratio is small. In alumina, the normal stresses generated along $x$ - and $z$-axes of the structure seem not dependent on the form of the site of interface defect. In this component, the stress induced according to the direction is not very sensitive to the form of this site. The Von Mises stress grows with the increase in $x / y$ ratio. The stress concentration factor decreases with the increase of this ratio.

- The intensity and the distribution of the normal, tangential and equivalent stress depend on the defect-defect interdistance. Bringing together these sites one towards the other, lead to an intensification of these constraints. These stresses are overall higher as the defects are very close to each other.

\section{REFERENCES}

[1] Boutabout, B., Chama, M., Bouiadjra, B.A.B., Serier, B., Lousdad, A. (2009). Effect of thermomechanical loads on the propagation of crack near the interface brittle/ductile, Comput. Mater. Sci., 46(4), pp. 906-911. DOI: $10.1016 /$ j.commatsci.2009.04.039.

[2] Yang, Y.Y., Munz, D. (1997). Stress singularities in a dissimilar materials joint with edge tractions under mechanical and thermal loadings, Int. J. Solids Struct., 34(10), pp. 1199-1216. DOI: 10.1016/S0020-7683(96)00097-2.

[3] Nikbakt, S., Kamarian, S., Shakeri, M. (2018). A review on optimization of composite structures Part I: Laminated composites, Compos. Struct., 195, pp. 158-185. DOI: 10.1016/j.compstruct.2018.03.063.

[4] Williamson, R.L., Rabin, B.H., Byerly, G.E. (1995). FEM study of the effects of interlayers and creep in reducing residual stresses and strains in ceramic-metal joints, Compos. Eng, 5(7), pp. 851-863.

DOI: 10.1016/0961-9526(95)00035-L.

[5] You, X.M., Liang, L.H., Wei, Y.G. (2018). The atomistic simulation study of Ag/MgO interface tension fracture, Comput. Mater. Sci., 142, pp. 277-284. DOI: 10.1016/j.commatsci.2017.10.029.

[6] Nascimento, R.M. do., Martinelli, A.E., Buschinelli, A.J.A. (2003). Review Article: recent advances in metal-ceramic brazing, Cerâmica, 49(312), pp. 178-198. DOI: 10.1590/S0366-69132003000400002.

[7] Li, V. (2004). Fracture mechanics of concrete structures: proceedings of the Fifth International Conference on Fracture Mechanics of Concrete and Concrete Structures, Vail Colorado, \{USA\}, April 12 - 16.

[8] Drake, J.T., Williamson, R.L., Rabin, B.H. (1993). Finite element analysis of thermal residual stresses at graded ceramic/metal interfaces, part II: optimization for residual stress reduction, J. Appl. Phys., 74(2), pp. 1321-1326. DOI:10.1063/1.354911. 
[9] Gill, S.C., Clyne, T.W. (1990). Stress distributions and material response in thermal spraying of metallic and ceramic deposits, Metall. Trans. B, 21(2), pp. 377-385. DOI: 10.1007/BF02664205.

[10] Suganuma, K., Miyamoto, Y., Koizumi, M. (1988). Joining of Ceramics and Metals, Annu. Rev. Mater. Sci., 18(1), pp. 47-73. DOI: 10.1146/annurev.ms.18.080188.000403.

[11] Evans, A. G., Dalgleish, B. J. (1993). The fracture resistance of metal-ceramic interfaces, Materials Science and Engineering: A, 162(1-2), 1-13. DOI: 10.1016/0921-5093(90)90025-x.

[12] Elssner, G., Petzow, G. (1990). Metal/ceramic joining, ISIJ Int., 30(12), pp. 1011-1032. DOI: $10.2355 /$ isijinternational.30.1011.

[13] Serier, B. (1991). Etude et caractérisation des liaisons céramique-mètal élaborées par solid state bonding, application au couple $\mathrm{Ag} / \mathrm{Al}_{2} \mathrm{O}_{3}$. Available at: http://www.theses.fr/1991ECDL0019.

[14] Sérier, B., Berroug, A., Juvé, D., Tréheux, D., Moya, E.G. (1993). Silver-alumina solid state bonding: Study of diffusion and toughness close to the interface, J. Eur. Ceram. Soc., 12(5), pp. 385-390. DOI: 10.1016/0955-2219(93)90008-F.

[15] Fekirini, H., Serier, B., Bouafia, F., Bouiadjra, B.A.B., Hayat, S.S., Bouafia, S.A. (2012). Effect of precipitateprecipitate interaction on residual stress in welded structure, Comput. Mater. Sci., 65, pp. 207-215. DOI: 10.1016/j.commatsci.2012.06.005.

[16] Souad, S., Serier, B., Bouafia, F., Bouidjra, B.A.B., Hayat, S.S. (2013). Analysis of the stresses intensity factor in alumina-Pyrex composites, Comput. Mater. Sci., 72, pp. 68-80. DOI: 10.1016/j.commatsci.2013.01.030.

[17] Bouafia, F., Serier, B., Serier, N., Hayat, S.S. (2014). Effect of Density and Pointed Corner Degree of Pore on Local Stress in Welded Structures: Defect in Marine Structures, ISRN Mech. Eng., 2014, pp. 1-7. DOI: $10.1155 / 2014 / 834659$.

[18] Dassaut Systèmes Simulia Corp-Abaqus/CAE 6.11 User's Manual. Available at: https://www.3ds.com/productsservices/simulia.

[19] Huo, Y., Lee, C.C. (2016). The growth and stress vs. strain characterization of the silver solid solution phase with indium, J. Alloys Compd., 661, pp. 372-379. DOI: 10.1016/j.jallcom.2015.11.212. 